\title{
Development Trend of Ecological and Green Visual Communication Design Education in the New Era
}

\author{
Jian Rao*, Jingwen Huang \\ School of Art and Design, Hubei University of Technology, Wuhan, Hubei, China \\ *Corresponding Author.
}

\begin{abstract}
:
In recent years, green design has experienced rapid development, but also exposed a series of problems such as high cost, lack of humanization, low recycling rate and so on. For these drawbacks, designers have an unavoidable responsibility. This paper analyzes the existing problems in green design. From the change of design thinking, the eco-friendly design method is explored. In this paper, the design from material selection to production, and then to the recovery of the whole process of overall consideration, follow the principle of reduction, reuse, recycling. The content of visual communication design can be roughly classified. According to their own characteristics, the best design scheme is selected. Through the application of different media, replace the high pollution, high consumption of paper printing. It is proposed that the large-scale promotion of environmental protection materials can be realized by simplifying the quantity and types of materials. At the same time, this paper expounds the implementation method of green design education in art design education in Colleges and universities. This paper fully analyzes the purpose and value of green design education from the curriculum and content, teaching methods, the specific implementation of teaching effect evaluation and evaluation. The results show that promoting sustainable development of green education can cultivate students' creativity, innovation and creative ability. A perfect green design education system and a correct concept of ecological civilization can be established.
\end{abstract}

Keywords: Green Design, Visual Communication Design, Art Design Education, Teaching Effect Evaluation.

\section{INTRODUCTION}

Design is responsible for creating a reasonable way of life for human beings, and also the task of exploring the harmonious relationship between human and nature and facing the future. The overall purpose of the research on green design of visual communication design is to realize the optimization of visual communication design, to establish a green ecological circle of visual communication design in social environment, to realize the benign, harmonious and sustainable development of design and society, audience, environment, culture and economy. Design is always for the public life [1-2]. Only in accordance with the psychological needs of the masses, bringing good social benefits and helping to create a good social atmosphere, visual communication design can achieve good economic benefits and obtain its own benign and long-term development [3]. Only by creating works that meet the aesthetic psychological needs of the 
audience and more humanized, and infusing unlimited green vitality into the design today with the creative spirit of not limited, unfettered and developing, can visual communication design better integrate into social life and promote the harmonious development of society.

The green concept is input into the blood of visual communication design, which means that visual communication art design must pursue a new integration. Through the green of visual communication design, the paper corrects the blind chaos of visual communication design and its own growth process and practical application, optimizes the development of visual communication design, makes visual communication more orderly and scientific, and finally completes the transformation of its best way. The paper discusses the visual pollution as visual enjoyment, and constructs a reasonable, optimized and green visual and spiritual space.

\section{OVERVIEW OF GREEN VISUAL COMMUNICATION DESIGN}

2.1 The meaning and theoretical basis of green visual communication design

1) The meaning of greening

The core concept of green design, which takes green as the attribute, is to create a design system that conforms to the law of ecological benign cycle [4]. The green design of visual communication, that is, under the guidance of green design concept, creates a visual communication design system which is in line with the benign cycle of social ecology. Specifically, it is to introduce the green design concept into the field of visual communication design [5]. From the perspective of green, we should start from the creative and performance of design, stimulate the design vitality, oppose the rigid imitation of design, oppose the piling of too many forms of languages, and realize the overall improvement of the life quality of the design subject.

The greening of visual communication design is the extension and concretization of the concept of green design in the field of visual communication design. To deeply understand the meaning of greening, it is necessary to have a deep understanding of green design. GreenDesign is an international design trend which appeared in 1980s. Green design is not a simple change of design style, nor a general adjustment of working methods, but a great change of design strategy. It is the performance of thinking about the relationship between nature, society and people in the fields of product design, production and circulation, extending from product manufacturing to product packaging, product promotion and product marketing which are closely related to products [6-9]. And progress has been extended to the whole society's awareness of green service and green culture, which is a whole that affects the whole society's production, consumption and culture.

In this increasingly commercialized and secularized era, our visual communication designers should keep a wise and clean heart, use scientific expression means, rich knowledge base, sincere and optimistic attitude, and come from the sense of maintaining and improving the vitality and spiritual connotation of design, and jointly promoting the green change of visual communication design. It makes visual communication design into an updated and benign life process. The greening of visual communication design, as a design idea that stands at the height of human and nature and returns to self-care, will bring visual communication design into a new realm and realize the harmony between design and human, society and nature (see Figure 1). 


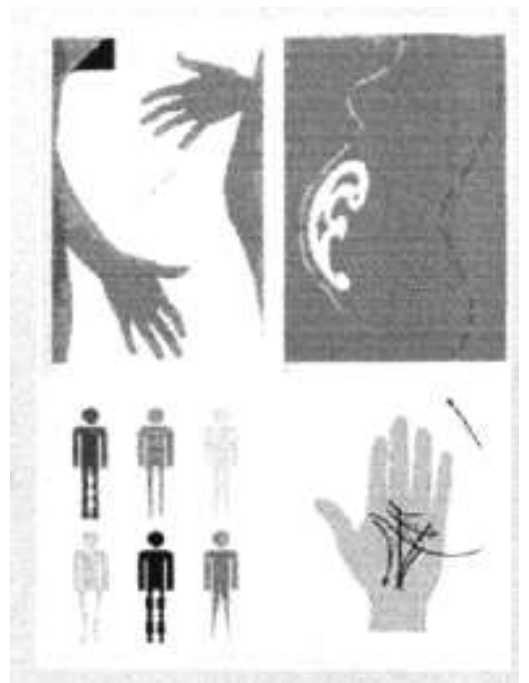

2) Theoretical basis

Fig 1: The series of "Design Love" designed by Lex Devinsky

The green research of visual communication design is based on the research and analysis of green design, humanized design, ecological design, appropriate design, ethical design, sustainable development and other design ideas and development concepts, extracting the positive and advanced significance of its ideas, and then integrating the specific realization of visual communication design. At the end of 1980s, there was a trend of secluded design. Green design reflects people's reaction to the environmental and ecological damage caused by modern technology and culture, and also reflects the return of designers' morality and social responsibility. Humanized design is a popular design that focuses on human needs, also known as humanistic design. In the design, human factors, such as human-computer relationship, consumer demand motivation, the impact of the use environment on people, are considered first, so that people and products can have a good and suitable interactive relationship. Humanistic design requires that the product in the shape, texture, color, structure, size and other aspects meet the needs of environmental protection and society, especially in line with the physiological and psychological characteristics of users, that is, in line with various requirements of Ergonomics (such as, conducive to people's physical and mental health, easy to reduce human fatigue, enhance safety performance and warning ability in dangerous situations, etc.). Ecological design is to bring environmental factors into the design, so as to help determine the direction of design decision. Ecological design requires that environmental factors should be considered in all stages of product development, so as to reduce the impact on the environment from the whole life cycle of the product, and ultimately lead to a more sustainable production and consumption system.

\subsection{The research purpose of green visual communication design}

The purpose of the green research of visual communication design is to use the concept of green design to guide the visual communication design in the current business information society environment, inject the elite and advanced ideas in green design into its blood, and complete the overall sublimation and transformation of visual communication design from creative conception to design performance. At the same time, under the guidance of the concept of green design, a visual communication design system is created which is in line with the benign cycle of social ecology. The overall goal of green research on visual communication design is to realize the optimization and development of visual communication design and to establish a well ordered social space visual order. Finally, the green ecological circle of visual 
communication design is established in the social environment to realize the benign, harmonious and sustainable development of design and society, audience, environment, culture and economy. According to the harmonious relationship, we should strengthen the visual law, promote the visual communication design to enter a new, scientific and optimized life stage, turn the visual pollution in the visual communication field into visual enjoyment, and create a green space for social material and cultural spiritual life!

Design will always serve the public life. Only by conforming to the psychological needs of the public, bringing good social benefits and helping to create a good social atmosphere, can visual communication design achieve good economic benefits and obtain its own benign and long-term development. Only by creating more humanized works that meet the aesthetic psychological needs of the audience, and injecting unlimited green vitality into today's design with unlimited, non solidified and constantly developing creative spirit, can visual communication design be better integrated into social life and promote the harmonious development of society. The introduction of green concept into the blood of visual communication design indicates that visual communication art design is bound to pursue a new integration. Through the greening of visual communication design, we can correct the blind and chaotic situation of visual communication design in its own growth process and practical application, optimize the development of visual communication design, make visual communication more orderly and scientific, and finally complete the transformation of its best way. Turn visual pollution into visual enjoyment, help to build a reasonable, optimized and green visual and spiritual space!

\section{REALIZATION OF GREEN VISUAL COMMUNICATION DESIGN}

\subsection{The realization goal of green visual communication design}

With the advent of knowledge economy, economic diversification and market development, China's society and economy give new opportunities and challenges to emerging industries. As a knowledge-based service industry and emerging interdisciplinary, design industry plays an important role in enterprise competition. The increasingly mature consumer market puts forward higher requirements for brand service, product packaging, advertising and image design, so as to promote the better development of design. The commercial advertisement, corporate identity design and beautiful packaging design of promotional products are all the products of the combination of market economy and visual communication design (see Figure 2 and figure 3). Design and social and economic development promote each other, and jointly open a green era of design economy. 


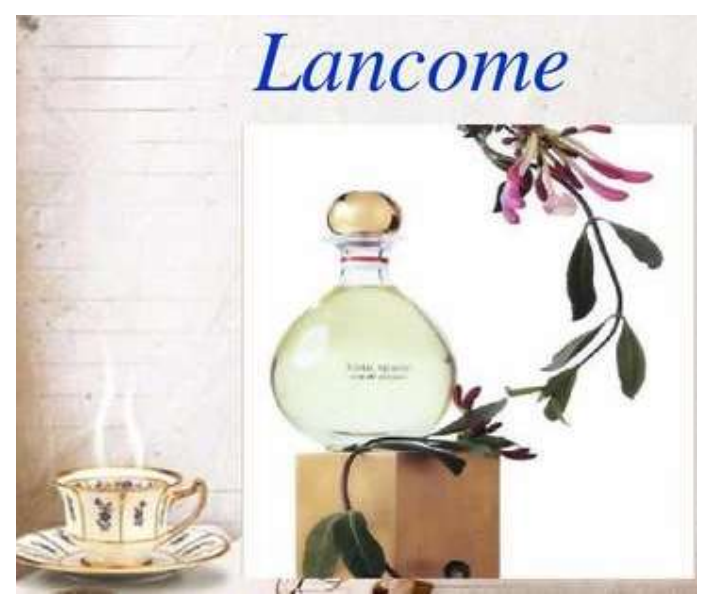

Fig 2: Perfume advertising

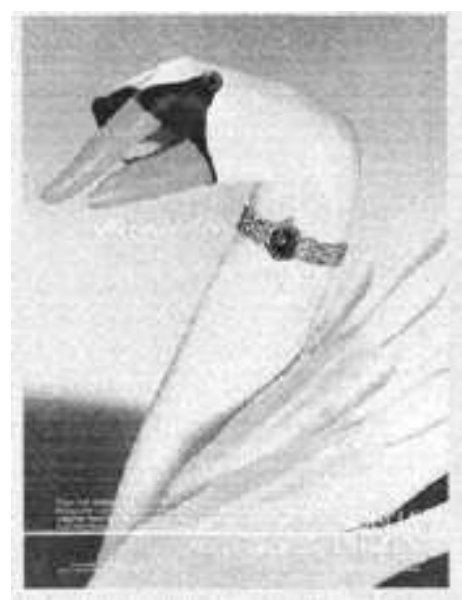

Fig 3: Watch advertising

The cultural absorption of visual communication design is still emphasized in the synthesis. It is mainly reflected in the fact that the cultural nature of design is mainly based on the material culture layer, and design is more sensitive to the changes of the material culture layer. This means that the progress of material civilization is more quickly penetrated into the visual communication design, and the creation of material civilization by design is more quickly fed back to the material civilization. Any material and spiritual activities of human beings are inevitably affected by cultural tradition, human background and social environment. As one of human activities, visual communication design is naturally influenced by culture (see Figure 4). At the same time, the results of design will also react on culture, become a part of the historical accumulation of culture, and thus spread.

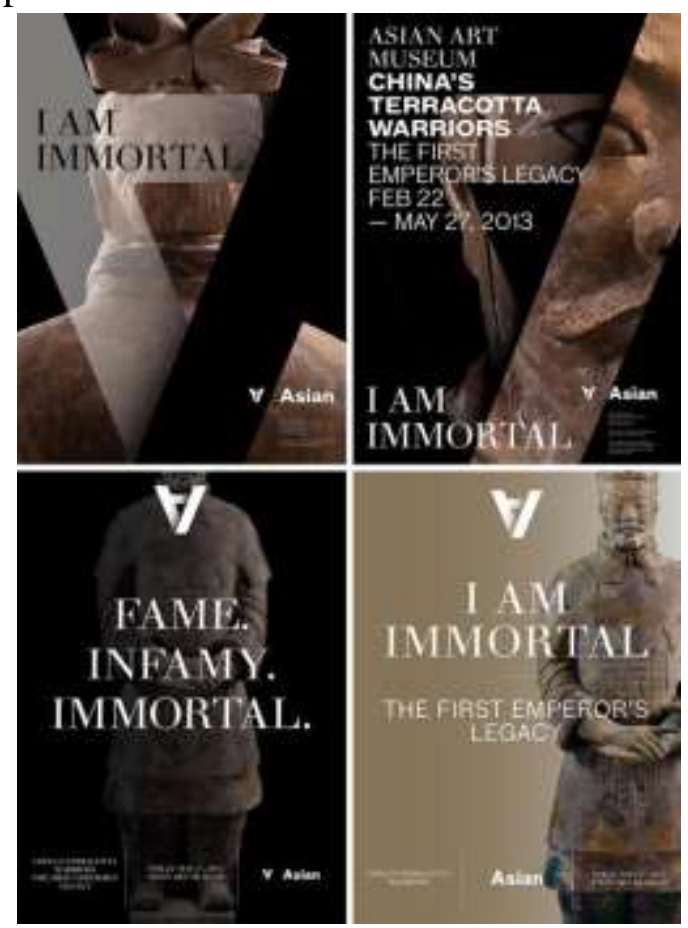

Fig 4: Poster of the third Asian Art Festival

3.2 The realization of green visual communication design

1. Raise the awareness of "green"

The greening of visual communication design is a new design challenge. It is not only the designer's 
business, but also an important thing for the public to realize the greening of visual communication design and establish an orderly visual environment in modern society. With the arrival of the green trend of thought, from the government leadership to the enterprises, the mass organizations and the majority of designers should feel their own responsibility and historical mission, strengthen the strength of green design, and actively carry out all kinds of work. It is a new task for us to grasp the green movement as a major event closely related to society, economy and life. The promotion of greenization involves the whole society, which not only needs the decision-making of the government and entrepreneurs, but also needs the rational thinking and strict implementation of designers. It requires high standards of their own design behavior, and more needs the participation and recognition of the public. The ecological values and moral ethics of the whole people will be the basis of the concept of greenization. Through the publicity and mobilization of the whole society, we should establish the social green concept of protecting the environment, respecting human nature and everyone's responsibility.

\section{Cultural design, improve the content of design culture}

The original meaning of the word "culture" refers to "human culture" and "to be educated by culture". With the continuous improvement of social civilization, more and more people with insight have realized the cultural connotation of design. With the process of social industrialization, visual communication design is becoming more and more commercial, but the inner quality of spiritual culture is gradually losing. There is a small and indivisible relationship between design and culture, and culture is the lifeblood of design. Only by cultural design can the cultural character and humanistic care of design be reflected. So we need to improve the cultural content of design, and inject infinite green vitality into visual communication design.

\section{Design innovation}

Innovation is the essential requirement of design. The reason why an excellent visual communication design works can stir people's heartstrings and arouse people's telepathy and resonance is that its creativity is fresh and special, its expression method is novel and unique, and it contains rich humanistic connotation. It can inspire people's thinking and imagination, and it can become a classic design only when it is noticed. Art design does not refuse the reference that is conducive to creativity, but the reference is not mechanically copied, and borrowing should be appropriate and ingenious. This kind of unprincipled reference is in fact rigid plagiarism. If it goes on like this, it will kill the vitality of design, seriously affect the benign development of visual communication design itself, and also bring unavoidable visual disaster to the audience. Therefore, designers must attach great importance to the innovation of visual communication design, and start with the innovation of design concept, visual language and technical expression, so as to convey information inaccurately and fully. Only by actively meeting the baptism of the information age, starting with the independent innovation of creative ideas and design performance, can we really promote the development of visual communication design towards the green direction.

\section{CONCLUSION}

Under the requirements of the development of society, times and design, visual communication design needs to stand at a new height of understanding, seek more scientific, reasonable and optimized development, and establish its own new life height and order. This will be a process of multi-party exploration. Green design has both idealistic color and strong sense of social responsibility. It is based on the understanding of the earth's ecology and human living environment. It is a design effort that is conducive to the sustainable 
development of society, the reduction of the earth's load, and the healthy and pure development of human living environment. This paper introduces the concept of green design into the field of visual communication design, uses the concept of green design to guide the visual communication design in today's business information society environment, corrects the blind and chaotic situation in the development process and practical application of visual communication design, and creates a visual communication design system in line with the social ecological virtuous cycle.

\section{REFERENCES}

[1] Lin, Yanping, et al. "A novel method in the design and fabrication of dental splints based on 3D simulation and rapid prototyping technology." International Journal of Advanced Manufacturing Technology, vol.28, no.9-10, pp.919-922, 2006.

[2] Kim, JiEon. "A Study on the Application of 3D Digital Technology to Producing Cyber Fashion Gallery." Molecular Neurobiology, vol.57, no.2, pp. 1-17, 2007.

[3] Yoshikawa, $\mathbf{N}$, et al. "Design and component test of a tiny processor based on the SFQ technology." IEEE Transactions on Applied Superconductivity, vol.13, no.2, pp. 441-445, 2003.

[4] Tong, Rongbai, et al. "Recent research progress in the synthesis and properties of burning rate catalysts based on ferrocene-containing polymers and derivatives." Journal of Organometallic Chemistry, vol.755, no.2, pp. 16-32, 2014.

[5] Shimada, Izumi , and J. F. Merkel . "Copper-Alloy Metallurgy in Ancient Peru." entific American, vol.265, no.1, pp. 80-861991.

[6] Luger A.. "Advances in Blue OLEDs Increase Efficiency and Lifetime." Critical Care Medicine, vol.14, no.5, pp. 458-461, 1986.

[7] Cavallaro, Rauno, L. Demasi, A. Passariello. "Nonlinear Analysis of PrandtlPlane Joined Wings: Effects of Anisotropy." AIAA Journal, vol.52, no.5, pp. 964-980, 2014.

[8] Segal, M. M. , et al. "Evidence-based decision support for neurological diagnosis reduces errors and unnecessary workup. " Journal of Child Neurology, vol.29, no.4, pp. 487-92, 2014.

[9] Lindqvist, Olav , and C. Tishelman . "Room for Death - International museum-visitors' preferences regarding the end of their life." Social Science \& Medicine, vol.139, no.2, pp. 1-8, 2015. 